\title{
Efeito da Associação Hipertiveoidismo- Castração no Osso de Ratas Adultas
}

\section{RESUMO}

Foi estudada a relação tireóide-gônadas e sua influência sobre a morfologia óssea de ratas Wistar, com cinco meses de idade, castradas e induzidas ao hipertireoidismo ou mantidas em eutireoidismo por período de 30,60 e 90 dias. Ratas não castradas foram mantidas nas mesmas condições e serviram como controle. Ao final de cada período, foram determinadas as concentrações plasmáticas de T4 livre, progesterona e estradiol. Os ossos de cada grupo foram submetidos às análises radiológica e histológica. O hipertireoidismo nas ratas não castradas levou à alteração da morfologia do osso, variável ao longo do período experimental, conduzindo, aos 60 dias, à perda de osso trabecular por aumento da reabsorção óssea. Aos 90 dias não houve perda óssea porque o aumento da reabsorção foi acompanhado por maior aposição óssea. Nas ratas eutireóideas castradas, a diminuição dos níveis de progesterona inibiu a aposição óssea, causando, aos 30 dias, pequena perda do osso trabecular das vértebras lombares e do osso alveolar, que se intensificou aos 60 e 90 dias, atingindo também o osso cortical. A administração de tiroxina nas ratas castradas reduziu a osteopenia decorrente da castração aos 60 dias, mas não aos 90 dias, quando a perda óssea foi mais extensa. Conclui-se que o hipoprogesteronismo e o hipoestrogenismo alteram o metabolismo ósseo e que a resposta do osso ao hipertireoidismo depende do perfil plasmático dos esteróides sexuais, do tempo de exposição e da configuração do tecido ósseo. (Arq Bras Endocrinol Metab 2004;48/6:875-884)

Descritores: Rata; Castração; Hipertireoidismo; Osso

\begin{abstract}
Bone Effects of the Association Hyperthyroidism-Castration of Adult Female Rats.

The relationship between thyroid, gonads and bone morphology was investigated in 5 month-old Wistar rats, castrated and kept in hyperthyroid or euthyroid state for periods of 30,60 and 90 days. A non-castrated control group was maintained in the same condition. At the end of each period, plasma concentrations of free T4, progesterone and estradiol were measured. The bones from each group were submitted to radiological and histological analysis. Hyperthyroidism in intact rats caused variation in bone morphology throughout the experiment, leading to loss of trabecular bone tissue at day 60 , due to increased bone resorption. At day 90 there was no bone loss, because the increase in bone resorption was accompanied by higher bone apposition. In castrated euthyroid rats reduction in progesterone levels inhibited the bone apposition, causing a slight loss of trabecular bone tissue in vertebrae and alveolar bone at day 30 , which was intensified at days 60 and 90 , affecting cortical bone tissue. The administration of thyroxine to castrated rats reversed osteopenia at days 30 and 60 , which did not occur at day 90 when bone loss was more extensive. In conclusion, hypoprogesteronism and hypoestrogenism alter bone metabolism and the bone response to hyperthyroidism depends on the plasma profile of
\end{abstract}

artigo original

\author{
Rogéria Serakides \\ Vera Alvarenga Nunes \\ Natália de Melo Ocarino \\ Ernane F. do Nascimento
}

Setor de Patologia do Departamento de Clinica e Cirurgia Veterinárias da Universidade Federal de Minas Gerais, Belo Horizonte, $M G$. 


\section{sex steroids, time of exposure and bone tissue config- uration. (Arq Bras Endocrinol Metab 2004;48/6:875- 884)}

\section{Keywords: Rat; Castration; Hyperthyroidism; Bone}

$\mathbf{O}^{\circ}$ OSSO É UM TECIDO DINÂMICO, em constante renovação, e sua integridade depende do equilíbrio entre os processos anabólicos (aposição) e catabólicos (reabsorção), de sorte que a perda desse equilíbrio altera a matriz e a mineralização ósseas $(1,2)$.

O paratormônio (PTH), o 1,25-diidroxicolecalciferol e a calcitonina são os principais reguladores da homeostasia mineral (3). Já o estrógeno, a tiroxina (T4) e a triiodotironina (T3) influenciam o metabolismo ósseo, controlando, de forma diferenciada, a reabsorção e a aposição ósseas (1). Tanto os hormônios tireoidianos quanto os esteróides sexuais regulam, nos osteoblastos, a expressão dos genes que codificam o colágeno do tipo I, fosfatase alcalina, osteopontina, osteocalcina e osteonectina e aumentam a diferenciação dos osteoblastos e a síntese e mineralização da matriz óssea $(1,4)$.

A relação entre disfunção tireoidiana e perda óssea foi descrita pela primeira vez há 100 anos por Von Recklinghausen (4). Anos mais tarde, biópsias de crista ilíaca e análises radiológicas demonstraram que as alterações ósseas no hipertireoidismo são similares às da osteíte fibrosa, osteoporose e osteomalacia (5). Entretanto, nas últimas décadas, vários relatos têm demonstrado que as alterações ósseas associadas com a tireotoxicose têm características distintas $(6,7)$.

Apesar dos osteoclastos não apresentarem receptores para os hormônios tireoidianos, a T3 estimula a reabsorção óssea, mas somente quando os níveis de T4 e T3 são elevados, à semelhança do que é observado no hipertireoidismo $(8,9)$. Portanto, muitos pesquisadores têm proposto que a perda óssea no hipertireoidismo é devido à excessiva reabsorção óssea $(10,11)$. Apesar do PTH estimular a reabsorção óssea e ser mais eficiente que T3 na ativação do catabolismo ósseo, a perda óssea determinada por esses hormônios ocorre por mecanismos distintos (4).

O hipertireoidismo parece aumentar a perda óssea na menopausa $(11,12)$ e este fato sugere que há interação entre tireóide e gônadas no controle do metabolismo ósseo e da homeostasia mineral. Mas há distintas opiniões sobre a resposta do tecido ósseo aos hormônios tireoidianos em indivíduos normais e hipogonádicos. O objetivo deste estudo foi caracterizar as alterações ósseas em ratas adultas hipertireóideas castradas e não castradas.

\section{MATERIAL E MÉTODOS}

Um total de 108 ratas Wistar com cinco meses de idade foi distribuído em caixas plásticas com cinco ratas/caixa e mantidas no mesmo ambiente com 12 horas de escuro/claro. Os animais foram alimentados com ração comercial com $22 \%$ de proteína, $1,4 \%$ de cálcio e $0,6 \%$ de fósforo. A ração e a água foram fornecidas ad libitum.

Após 30 dias de adaptação ao ambiente e à alimentação, as ratas foram aleatoriamente separadas em quatro grupos de 27, sendo que dois grupos foram castrados de acordo com o protocolo aprovado pelo Comitê de Ética Animal da Universidade Federal de Minas Gerais: 24 horas antes da cirurgia todas as ratas receberam $0,1 \mathrm{ml} / 100 \mathrm{~g}$ de pentabiótico intramuscular e imediatamente antes da cirurgia receberam $0,2 \mathrm{mg} / \mathrm{kg}$ de atropina por via subcutânea. A anestesia foi realizada pela associação de $40 \mathrm{mg} / \mathrm{kg}$ de quetamina com $10 \mathrm{~g} / \mathrm{kg}$ de xilazina. Duas incisões de aproximadamente $1 \mathrm{~cm}$ de comprimento foram realizadas na região abdominal dorso-lateral e os ovários foram expostos e removidos.

Uma semana após a castração, um grupo castrado e outro não castrado foram induzidos ao hipertireoidismo mediante administração diária por sonda oro-gástrica de $50 \mu \mathrm{g}$ /animal de L-tiroxina (Armesham International, Buckinghamshire, Inglaterra), diluída em $5 \mathrm{ml}$ de água destilada. Os grupos eutireóideos receberam $5 \mathrm{ml}$ de água destilada como placebo, administrada da mesma forma e nos mesmos horários.

Quatro grupos foram constituídos: (1) controle (2) castrado, (3) hipertireóideo e (4) hipertireóideo castrado. Aos 30, 60 e 90 dias de tratamento, amostras de sangue foram colhidas em nove ratas/grupo por punção cardíaca para sacrifício seguido de necropsia.

Todo o esqueleto foi colhido para análises radiológica e histológica. A carcaça sem os membros esquerdos foi radiografada na posição látero-lateral (filme Kodak TMG/RAl, 18X24 cm, 24kvs, 5 segundos) em aparelho de micro-radiografia e em seguida fixada em formalina a $10 \%$ neutra e tamponada.

As radiografias foram avaliadas sob negatoscópio e do fêmur foram tomadas as medidas do comprimento (epífise a epífise) e da largura da cortical, do canal medular e da largura total do osso, na diáfise média, utilizando régua milimétrica e lupa. Para a obtenção do índice cortical (IC), foram utilizadas as medidas da largura total do fềmur (T) e da largura da cavidade medular (M), empregando-se a seguinte fór- 
mula: $\mathrm{IC}=(\mathrm{T}-\mathrm{M}) / \mathrm{T}$

Após 30 dias de fixação, os esqueletos foram cuidadosamente dissecados para individualização dos ossos. Crânio, maxila, mandíbula, vértebra (todos os segmentos) e ossos longos (fêmur, tíbia, úmero e rádio) foram descalcificados em solução de ácido fórmico a $10 \%$ em pH 4,5 sob vácuo moderado. Depois de finalizada a descalcificação, controlada por raio X, seguida de lavagem em água corrente por 24 horas, os ossos foram longitudinalmente seccionados e processados pela técnica rotineira de inclusão em parafina. Secções histológicas foram coradas pela hematoxilinaeosina e analisadas por microscopia óptica.

As concentrações plasmáticas de T4 livre e progesterona foram determinadas pela técnica da quimioluminescência (Access Immunoassay System, Sanofi Diagnostics Pasteur Inc., Chaska, MN, EUA). O estradiol plasmático foi medido pela fluorimetria (Delphia, Wallac Oy, Turku, Finlândia), ambos em sistema totalmente automático e de acordo com as recomendações do fabricante dos kits.

$\mathrm{O}$ delineamento experimental foi o inteiramente ao acaso, em esquema fatorial $4 \times 3$ (quatro grupos e três períodos). A média e o desvio-padrão das variáveis mensuradas foram determinados $\mathrm{e}$ as médias foram comparadas pelo teste $t$ de Student. Valores menores que 0,05 foram considerados significativos (13).

\section{RESULTADOS}

\section{Análise Hormonal}

Os resultados das análises hormonais nos quatro grupos e nos três períodos de observação estão apresentados nas tabelas 1 a 3 . Os valores médios de estradiol no grupo castrado diminuíram somente aos 90 dias de experimento (tabela 1), mas os valores plasmáticos de progesterona reduziram a partir dos 30 dias e per- maneceram baixos até os 90 dias, o que confirma que as ratas castradas estavam em estado hipogonádico durante todo o experimento. $\mathrm{O}$ hipoprogesteronismo aumentou os valores de T4 livre nas ratas eutireóideas castradas, tornando-os semelhantes aos das ratas hipertireóideas aos 60 dias. Mas as ratas tratadas com tiroxina apresentaram níveis de T4 livre maiores que o das ratas controle aos 30,60 e 90 dias, confirmando a indução do hipertireoidismo por todo o período experimental (tabela 3 ).

\section{Análise Radiológica}

Aos 30 dias não havia diferença radiológica entre grupos, mas aos 60 dias, $40 \%$ das ratas hipertireóideas e $60 \%$ das ratas castradas apresentaram redução da radiopacidade da última vértebra torácica e das primeiras vértebras lombares.

Aos 90 dias, as vértebras lombares de ratas hipertireóideas não mostraram diferenças radiológicas comparadas às do grupo controle, mas a cortical do fêmur apresentava-se irregularmente mais espessa (tabela 4). Neste mesmo período, a perda de radiopacidade estava presente em $90 \%$ dos ossos das ratas castradas, estendendo-se para a tíbia proximal. Também houve redução da espessura da cortical do fêmur, mas essa redução não foi significativa (tabela 4).

A associação hipertireoidismo-castração causou poucas alterações ósseas radiológicas aos 60 dias. Somente $25 \%$ das ratas apresentou discreta redução da radiopacidade das vértebras lombares e torácicas. $\mathrm{O}$ restante, ou seja, $75 \%$ das ratas, tinha características radiológicas semelhantes àquelas do grupo controle. Mas a cortical do fềmur apresentava-se irregularmente mais espessa que a do grupo castrado (tabela 4). Aos 90 dias, $90 \%$ das ratas hipertireóideas castradas mostrou perda extensa da radiopacidade óssea com significativa redução da espessura da cortical (tabela 4)

Tabela 1. Média e desvio-padrão dos valores plasmáticos de estradiol ( $\mathrm{nmol} / \mathrm{l}$ ) por grupo e período de tratamento.

\begin{tabular}{lccc}
\hline Grupo & \multicolumn{3}{c}{ Valores plasmáticos de estradiol (nmol/I) } \\
& $\mathbf{3 0}$ dias & $\mathbf{6 0}$ dias & $\mathbf{9 0}$ dias \\
\hline Controle & $0,13 \pm 0,08 \mathrm{Aa}$ & $0,12 \pm 0,06 \mathrm{Aa}$ & $0,12 \pm 0,05 \mathrm{Aa}$ \\
Castrado & $0,10 \pm 0,02^{\mathrm{Aa}}$ & $0,09 \pm 0,02 \mathrm{Aa}$ & $0,06 \pm 0,03^{\mathrm{Ab}}$ \\
Hipertireóideo & $0,13 \pm 0,06 \mathrm{Aa}$ & $0,12 \pm 0,04 \mathrm{Aa}$ & $0,13 \pm 0,08 \mathrm{Aa}$ \\
Hipertireóideo castrado & $0,10 \pm 0,04 \mathrm{Aa}$ & $0,11 \pm 0,03 \mathrm{Aa}$ & $0,09 \pm 0,05 \mathrm{Aab}$ \\
\hline
\end{tabular}

* Médias com letras maiúsculas iguais na linha e letras minúsculas iguais na coluna não diferem entre si $(P \geq 0,05)$. 
Tabela 2. Média e desvio-padrão dos valores plasmáticos de progesterona $(\mathrm{ng} / \mathrm{ml})$ por grupo e período de tratamento.

\begin{tabular}{|c|c|c|c|}
\hline \multirow[t]{2}{*}{ Grupo } & \multicolumn{3}{|c|}{ Valores plasmáticos de progesterona $(\mathrm{ng} / \mathrm{ml})$} \\
\hline & 30 dias & 60 dias & 90 dias \\
\hline Controle & $27,49 \pm 10,01^{A a}$ & $30,08 \pm 9,49 A a$ & $21,08 \pm 13,84^{A a}$ \\
\hline Castrado & $12,03 \pm 7,68 \mathrm{Abc}$ & $11,15 \pm 7,67^{\mathrm{Ab}}$ & $10,23 \pm 7,97 \mathrm{Ab}$ \\
\hline Hipertireóideo & $21,33 \pm 15,93 \mathrm{Aab}$ & $23,64 \pm 14,71 \mathrm{Aa}$ & $18,16 \pm 12,34^{\mathrm{Aab}}$ \\
\hline Hipertireóideo castrado & $8,58 \pm 9,40^{A c}$ & $9,08 \pm 7,35 \mathrm{Ab}$ & $8,76 \pm 4,93 \mathrm{Ab}$ \\
\hline
\end{tabular}

* Médias com letras maiúsculas iguais na linha e letras minúsculas iguais na coluna não diferem entre si $(P \geq 0,05)$.

Tabela 3. Média e desvio-padrão dos valores plasmáticos de tiroxina livre (ng/dl) por grupo e período de tratamento.

\begin{tabular}{lccc}
\hline Grupo & \multicolumn{2}{c}{ Valores plasmáticos de tiroxina livre (ng/dl) } \\
& $\mathbf{3 0}$ dias & $\mathbf{6 0} \mathbf{~ d i a}$ & $\mathbf{9 0}$ dias \\
\hline Controle & $2,18 \pm 0,48 \mathrm{Ac}$ & $1,64 \pm 0,40 \mathrm{Ac}$ & $1,71 \pm 0,39 \mathrm{Ad}$ \\
Castrado & $2,61 \pm 0,54 \mathrm{Abc}$ & $2,77 \pm 1,01 \mathrm{Ab}$ & $2,60 \pm 0,57 \mathrm{Ac}$ \\
Hipertireóideo & $3,11 \pm 0,77 \mathrm{Ab}$ & $3,45 \pm 1,28 \mathrm{ABb}$ & $4,18 \pm 0,93 \mathrm{Bb}$ \\
Hipertireóideo castrado & $4,99 \pm 0,80^{\mathrm{Aa}}$ & $5,02 \pm 1,05 \mathrm{Aa}$ & $5,64 \pm 1,13 \mathrm{Aa}$ \\
\hline
\end{tabular}

* Médias com letras maiúsculas iguais na linha e letras minúsculas iguais na coluna não diferem entre si $(P \geq 0,05)$.

Tabela 4. Média e desvio-padrão da espessura da cortical na região da diáfise média do fêmur direito ( $\mathrm{mm}$ ), por grupo e período de tratamento.

\begin{tabular}{|c|c|c|c|}
\hline \multirow[t]{2}{*}{ Grupo } & \multicolumn{3}{|c|}{ Espessura da cortical da diáfise média do fêmur (mm) } \\
\hline & 30 dias & 60 dias & 90 dias \\
\hline Controle & $1,56 \pm 0,17^{\mathrm{Aa}}$ & $1,61 \pm 0,22 \mathrm{Aab}$ & $1,50 \pm 0,00 \mathrm{Ab}$ \\
\hline Castrado & $1,67 \pm 0,25^{A a}$ & $1,56 \pm 0,17^{A B b}$ & $1,39 \pm 0,22^{\mathrm{Bbc}}$ \\
\hline Hipertireóideo & $1,67 \pm 0,35 \mathrm{Aa}$ & $1,63 \pm 0,23 \mathrm{Aab}$ & $1,83 \pm 0,25 \mathrm{Aa}$ \\
\hline Hipertireóideo castrado & $1,67 \pm 0,35^{A a}$ & $1,78 \pm 0,26 \mathrm{Aa}$ & $1,28 \pm 0,26^{\mathrm{Bbc}}$ \\
\hline
\end{tabular}

* Médias com letras maiúsculas iguais na linha e letras minúsculas iguais na coluna não diferem entre si $(P \geq 0,05)$.

Tabela 5. Média e desvio-padrão do índice cortical do fêmur direito, por grupo e período de tratamento.

\begin{tabular}{lccc}
\hline Grupo & \multicolumn{3}{c}{ índice cortical do fêmur } \\
& $\mathbf{3 0}$ dias & $\mathbf{6 0}$ dias & $\mathbf{9 0}$ dias \\
\hline Controle & $0,51 \pm 0,02^{\mathrm{Aa}}$ & $0,53 \pm 0,06^{\mathrm{Aa}}$ & $0,50 \pm 0,00^{\mathrm{Aab}}$ \\
Castrado & $0,56 \pm 0,09^{\mathrm{Aa}}$ & $0,48 \pm 0,05^{\mathrm{Ba}}$ & $0,46 \pm 0,09^{\mathrm{Bbc}}$ \\
Hipertireóideo & $0,53 \pm 0,10^{\mathrm{Aa}}$ & $0,54 \pm 0,07^{\mathrm{Aa}}$ & $0,54 \pm 0,05^{\mathrm{Aa}}$ \\
Hipertireóideo castrado & $0,55 \pm 0,10^{\mathrm{Aa}}$ & $0,54 \pm 0,06^{\mathrm{Aa}}$ & $0,44 \pm 0,08^{\mathrm{Bc}}$ \\
\hline
\end{tabular}

* Médias com letras maiúsculas iguais na linha e letras minúsculas iguais na coluna não diferem entre si $(P \geq 0,05)$.

e do índice cortical do fềmur (tabela 5).

\section{Análise Histológica}

\section{Grupo Castrado}

A análise histológica, mais precisa que a avaliação radiológica, permitiu que as alterações ósseas fossem detectadas mais cedo e em maior número de ratas. Já aos 30 dias, as ratas eutireóideas castradas mostraram perda óssea coincidente com a redução dos valores plasmáticos de progesterona (tabela 2). A placa epifisária dos ossos longos e das vértebras apresentava-se 
Tabela 6. Média e desvio-padrão do comprimento do fêmur direito $(\mathrm{cm})$, por grupo e período de observação.

\begin{tabular}{lccc}
\hline Grupo & \multicolumn{3}{c}{ Comprimento do fêmur (cm) } \\
& $\mathbf{3 0}$ dias & $\mathbf{6 0}$ dias & $\mathbf{9 0}$ dias \\
\hline Controle & $3,47 \pm 0,14^{\mathrm{Aa}}$ & $3,47 \pm 0,11^{\mathrm{Ab}}$ & $3,49 \pm 0,10^{\mathrm{Aa}}$ \\
Castrado & $3,56 \pm 0,08 \mathrm{Aa}$ & $3,61 \pm 0,12^{\mathrm{Aa}}$ & $3,57 \pm 0,13^{\mathrm{Aa}}$ \\
Hipertireóideo & $3,48 \pm 0,07^{\mathrm{Ba}}$ & $3,51 \pm 0,16^{\mathrm{ABb}}$ & $3,59 \pm 0,12^{\mathrm{Aa}}$ \\
Hipertireóideo castrado & $3,49 \pm 0,11^{\mathrm{Aa}}$ & $3,52 \pm 0,10^{\mathrm{Aab}}$ & $3,55 \pm 0,10^{\mathrm{Aa}}$ \\
\hline
\end{tabular}

* Médias com letras maiúsculas iguais na linha e letras minúsculas iguais na coluna não diferem entre si $(P \geq 0,05)$.

bem diferenciada e semelhante à do grupo controle, mas as trabéculas epifisárias e metafisárias no fêmur proximal e distal, tíbia proximal e vértebras lombares apresentavam-se discretamente delgadas, em número reduzido e algumas vezes fragmentadas. Os osteoblastos eram atrofiados e estavam presentes em número reduzido. Os osteócitos profundos apresentavam-se ora ativos (volumosos e alojados em uma lacuna ampla com margem lacunar e matriz adjacente intensamente basofílicas) e ora inativos (pequenos, alojados em lacunas estreitas e sem basofilia da margem lacunar e da matriz perilacunar). Escavações subperiosteais pequenas com osteoclasia e fibroplasia discretas foram observadas nas vértebras lombares e na região distal do fêmur. Na maxila e mandíbula, as cristas interdentárias apresentavam várias e pequenas escavações, mas poucos osteoclastos ativos foram observados.

Aos 60 e 90 dias, as alterações se intensificaram, ficando marcante a osteopenia. Ao contrário do grupo controle (figura 1), aos 90 dias havia redução da dife-

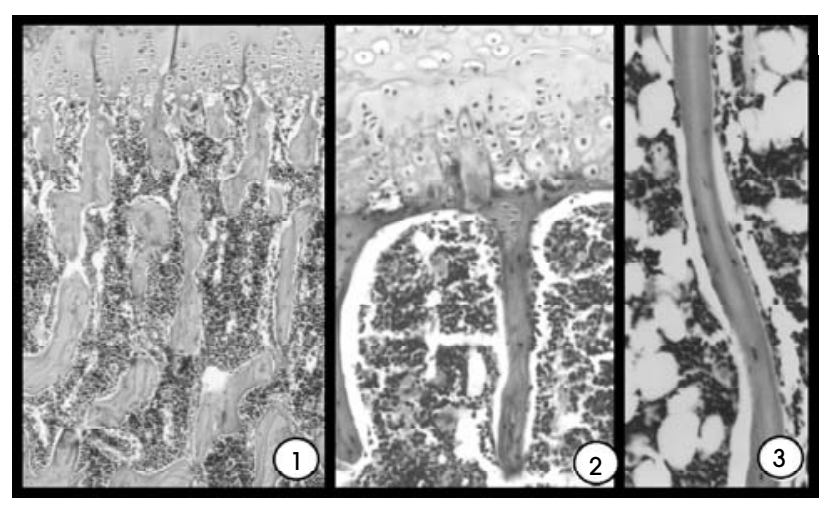

Figura 1. Rata controle (metáfise proximal da tíbia com trabéculas espessas e confluentes. HE, 107x).

Figura 2. Rata castrada aos 90 dias. Vértebra torácica com placa epifisária delgada, pobremente diferenciada e presença de placa óssea terminal distal. HE, 214x.

Figura 3. Rata castrada aos 90 dias. Epífise proximal do úmero com trabécula delgada coberta por osteoblastos achatados e inativos. HE, 257x. renciação da placa epifisária dos ossos longos e vértebras. A esponjosa primária era praticamente inexistente e uma placa óssea terminal distal selava a cartilagem epifisária em vários pontos (figura 2). As suturas dos ossos chatos eram delgadas e pobremente celularizadas. O crescimento ósseo longitudinal foi afetado pela castração em intensidade variável ao longo do período experimental. Aos 60 dias, a proliferação dos condrócitos era pequena, mas havia melhor diferenciação, resultando em maior comprimento do fêmur (tabela 6). Aos 90 dias, os condrócitos eram menos diferenciados, havendo retardo do crescimento linear, ficando o comprimento do fềmur similar ao do controle (tabela 6).

As trabéculas epifisárias e metafisárias eram poucas, delgadas e fragmentadas, com cobertura osteoblástica reduzida e formada por osteoblastos fusiformes e inativos (figura 3). Os osteócitos profundos apresentavam-se ora ativos, ora inativos. As cavidades de reabsorção subperiosteais foram observadas no fêmur e nas vértebras, mas havia poucos osteoclastos. A cortical dos ossos longos progressivamente tornava-se mais delgada, com alargamento do canal medular e o periósteo apresentava-se delgado e com redução da celularidade. Os ossos da maxila e mandíbula também apresentaram osteopenia com características semelhantes à dos demais ossos desse grupo, mas de grau intenso.

\section{Grupo Hipertireóideo}

$\mathrm{O}$ hipertireoidismo não alterou a morfologia óssea $\mathrm{em}$ ratas não castradas aos 30 dias, mas induziu intensa perda de tecido ósseo trabecular aos 60 dias. As trabéculas metafisárias do fêmur, tíbia, úmero e vértebras lombares e torácicas apresentavam-se muito delgadas e fragmentadas (figura 4). A maioria dos osteócitos profundos apresentava-se volumosos e localizados dentro de uma ampla lacuna (figura 5) com a borda lacunar muito basofílica. A superfície das trabéculas estava recoberta por osteoblastos ativos e algumas 


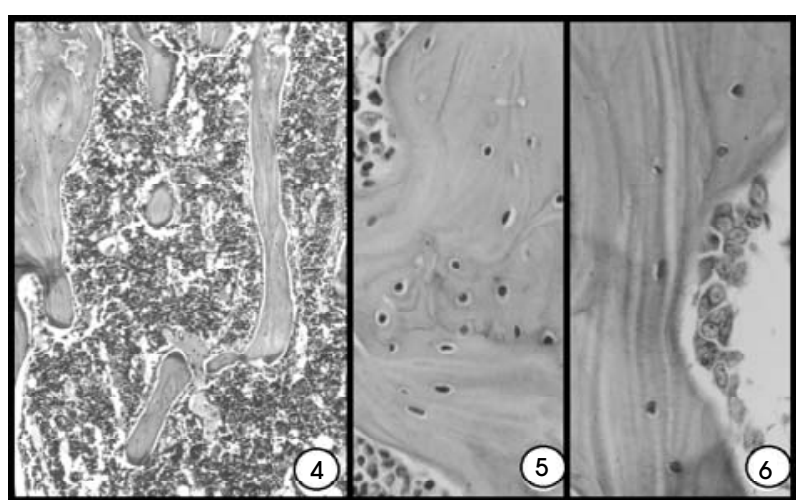

Figura 4. Rata hipertireóidea aos 60 dias. Vértebra torácica com trabéculas delgadas e fragmentadas. HE, 107x.

Figura 5. Rata hipertireóidea. Úmero proximal com osteócitos grandes alojados em lacunas alargadas. HE, 429x.

Figura 6. Rata hipertireóidea aos 90 dias. Vértebra torácica com trabécula recoberta por osteoblastos hiperplásicos e hipertrofiados. HE, 527x.

vezes inativos, e a medula óssea estava muito celularizada. O hipertireoidismo causou perda de tecido ósseo trabecular, mas preservou o osso cortical. A reabsorção subperiosteal nos ossos longos e vértebras era praticamente inexistente. A maxila apresentou intensa perda óssea com redução do osso alveolar e alargamento dos espaços intertrabeculares.

Entretanto, as lesões ósseas não progrediram até os 90 dias, quando os ossos não mostraram padrão claro de redução ou aumento da massa óssea pelas variações individuais. Nos ossos longos, vértebras e osso alveolar, havia trabéculas irregularmente espessas com redução da reabsorção óssea de permeio a trabéculas delgadas com estímulo da reabsorção óssea. Havia também alguns osteócitos degenerados e lacunas vazias. Foram também observadas hiperplasia e hipertrofia osteoblástica em algumas trabéculas de ossos longos e vértebras (figura 6). A cortical das vértebras e ossos longos apresentava-se irregularmente espessa com maior celularidade do periósteo.

\section{Grupo Hipertireóideo Castrado}

A tiroxina reverteu completamente a osteopenia da castração em todas as ratas aos 30 dias, e em 90\% delas aos 60 dias. A reversão da osteopenia ocorreu devido à redução da reabsorção óssea aliada ao aumento do crescimento ósseo longitudinal. Aos 60 dias, os ossos longos e as vértebras apresentavam placas epifisárias mais espessas, celularizadas e melhor diferenciadas. O crescimento ósseo foi restabelecido, houve penetração vascular e erosão da cartilagem da placa epifisária, e a esponjosa primária estava presente novamente (figura 7). As suturas, assim como as car- tilagens de crescimento, apresentavam-se mais celularizadas e ativas com neoformação óssea. Apesar da presença esporádica de trabéculas finas e fragmentadas no fềmur, tíbia e vértebras lombares e torácicas, a característica dominante era a de trabéculas irregularmente espessas cobertas por osteoblastos ora ativos, ora inativos (figura 8). A cortical também apresentavase irregularmente mais espessa, e a medula óssea estava mais celularizada. Os ossos faciais, especialmente o osso nasal (conchas), estavam mais espessos (figura 9) que o das ratas eutireóideas castradas (figura 10) e eram similares ao das ratas controle (figura 11).

Surpreendentemente, o incremento do tecido ósseo não continuou até os 90 dias, quando foi observada osteopenia de grau semelhante ao das ratas eutireóideas castradas, mas mais extensa, ou seja, afetando maior número de unidades esqueléticas. Nas vértebras, as trabéculas estavam presentes em número reduzido, eram delgadas e fragmentadas (figura 12) e cobertas por osteoblastos inativos, ao contrário do grupo controle. Os osteócitos alternavam entre as for-

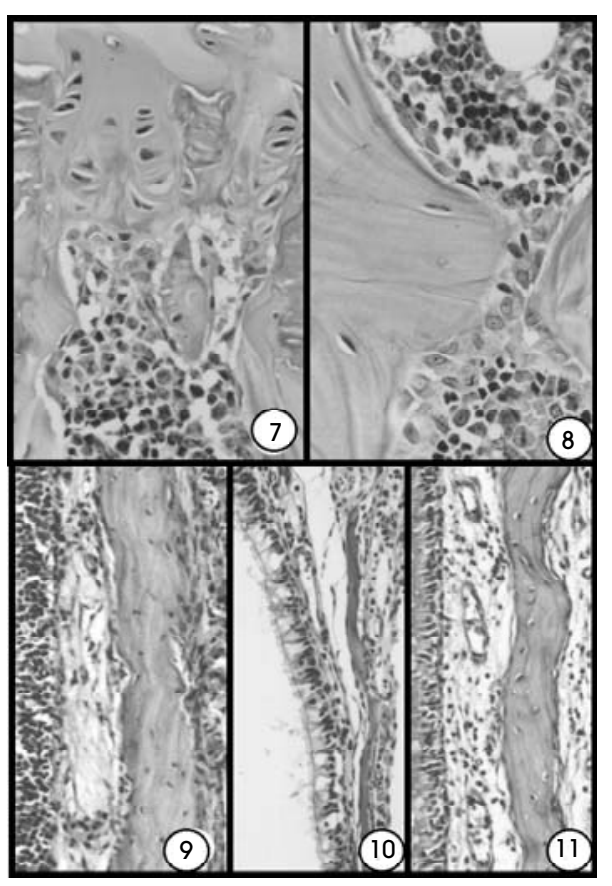

Figura 7. Rata hipertireóidea castrada aos 60 dias. Vértebra torácica com placa epifisária bem diferenciada e com retorno da invasão vascular. HE, 429x.

Figura 8. Rata hipertireóidea castrada aos 60 dias. Trabécula espessa coberta por osteoblastos ativos e inativos. HE, 549x.

Figura 9. Rata hipertireóidea castrada aos 60 dias com osso nasal mais espesso que o das ratas eutireóideas castradas (figura 10) e semelhante ao das ratas controle (figura 11). HE, 257x. 


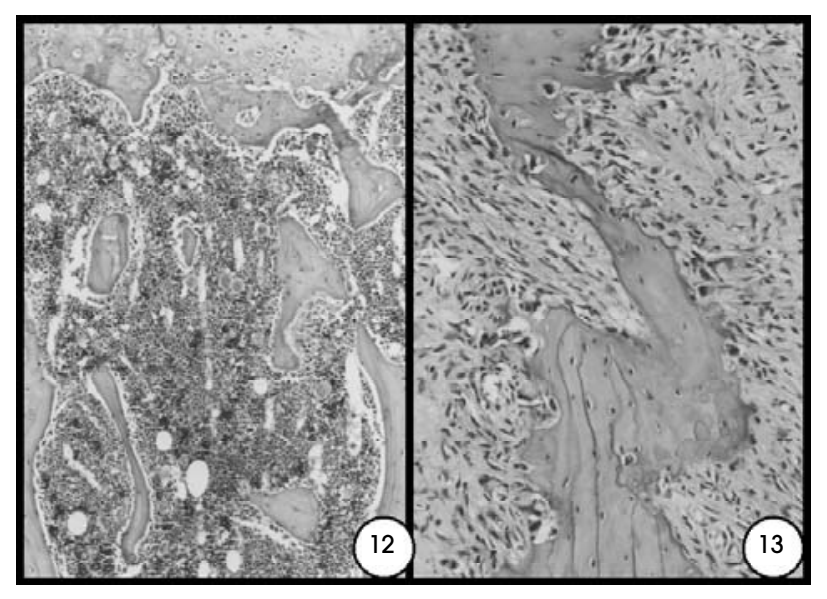

Figura 12. Rata hipertireóidea castrada aos 90 dias. Vértebra lombar com penetração vascular da placa epifisária, deslocamento da placa óssea terminal distal, com pequeno número de trabéculas metafisárias e sem esponjosa primária. HE, 132x.

Figura 13. Rata hipertireóidea castrada aos 90 dias. Mandíbula com reabsorção do osso alveolar por osteólise osteocítica associada à osteoclasia e proliferação de tecido conjuntivo denso nas áreas de escavação. HE, 214x.

mas ativas e inativas. Apesar do fềmur, tíbia e úmero apresentarem placas epifisárias bem diferenciadas, com deslocamento da placa óssea terminal distal, a esponjosa primária apresentava-se delgada. As trabéculas epifisárias estavam em número reduzido, delgadas e fragmentadas, e a cortical do fêmur apresentava redução da espessura, com redução do índice cortical, tal como já demonstrado anteriormente (tabela 5). O osso alveolar e todos os segmentos vertebrais mostraram osteopenia mais intensa quando comparada à dos ossos longos. As cavidades de reabsorção eram numerosas no osso alveolar, apesar da osteoclasia ser moderada. Em uma rata, a reabsorção do osso alveolar era tão intensa que incitava a proliferação de tecido conjuntivo fibroso, a fim de substituir a perda óssea, semelhante às características da doença periodontal (figura 13).

\section{DISCUSSĀO}

A gênese da perda óssea no hipogonadismo é postulada como decorrente da maior responsividade do osso ao PTH, acelerando a reabsorção óssea $(14,15)$. Segundo alguns autores, a similaridade da morfologia do osso de ratas tratadas com PTH e de ratas castradas reafirma a participação do PTH na osteopenia decorrente da castração (15). No presente estudo, aos 30 e 60 dias, o aumento da reabsorção era pouco expressi- vo, e a osteopenia parece ter sido induzida muito mais pela diminuição da aposição óssea do que pelo aumento da reabsorção. Como apenas os níveis de progesterona estavam em declínio no período, podese afirmar que a osteoporose (menor aposição óssea) foi decorrente do hipoprogesteronismo, reafirmando a participação da progesterona no metabolismo ósseo, particularmente sobre a síntese da matriz óssea, aventada por outros autores $(1,4)$.

A progesterona também é reconhecida como um hormônio importante no metabolismo ósseo e mineral, possuindo receptores específicos nos osteoblastos. Mas sua ação sobre o osso ainda é pouco conhecida (1). Em ratas ovariectomizadas (16) e em mulheres após a menopausa (17), a administração de progesterona previne a diminuição da massa óssea. Sabe-se que a expressão dos seus receptores nos osteoblastos é estimulada pelo estrógeno, por isso alguns dos efeitos sobre o esqueleto que são atribuídos ao estrógeno podem, de fato, ser mediados pela progesterona (18). A progesterona estimula a proliferação e diferenciação das células osteoprogenitoras (19) e atua nos osteoblastos regulando a secreção de fatores de crescimento (20) e estimulando a aposição e a mineralização ósseas (1).

No entanto, aos 90 dias, quando também havia diminuição significativa dos valores plasmáticos de estradiol, aliado à diminuição da aposição, foi constatado aumento da reabsorção óssea, o que aponta para a importância do estrógeno neste processo. No entanto, o mecanismo pelo qual ocorre estímulo da reabsorção óssea no hipoestrogenismo é controverso e, segundo alguns pesquisadores, de natureza multifatorial (14). Interessante é que as alterações ósseas induzidas pela castração não se agravaram em intensidade dos 60 para os 90 dias, mas o aumento da reabsorção ocorrido aos 90 dias provavelmente resultaria em osteopenia mais intensa nos meses subseqüentes.

Como demonstrado anteriormente, o hipoprogesteronismo elevou os valores plasmáticos de T4 livre, tornando-os semelhantes, até os 60 dias, aos das ratas hipertireóideas intactas. Com isso, poderia se pensar que a perda óssea dos 30 e 60 dias após a castração seria resultante do aumento de T4 livre. No entanto, a osteopenia da castração decorreu principalmente da inibição da aposição óssea e a do hipertireoidismo decorreu do aumento da reabsorção. Assim, não há indícios de que a elevação plasmática de T4 livre, ocorrente no hipogonadismo, participe na gênese da osteopenia induzida pela deficiência de esteróides sexuais. Esta assertiva é também defendida por outros pesquisadores $(21,22)$. 
Alguns pesquisadores afirmam que, no rato, o crescimento longitudinal dos ossos ocorre durante toda a vida (23), enquanto outros autores discordam $(24,25)$. Durante todos os períodos de observação e em todos os grupos estudados, o crescimento longitudinal dos ossos era visível, embora variável em velocidade. As ratas castradas, por exemplo, apresentaram, aos 60 dias, maior comprimento do fềmur. Já foi verificado que a deficiência dos esteróides sexuais estimula a proliferação e a atividade de síntese dos condrócitos, acelerando o crescimento longitudinal dos ossos (1). Entretanto, as placas epifisárias das ratas castradas não demonstravam maior atividade da zona de proliferação, mas sim melhor diferenciação. Isso provavelmente influenciou a velocidade do crescimento longitudinal e poderia ter sido decorrente do aumento de T4 livre que acompanhou a castração neste período. $\mathrm{Na}$ realidade, o hipertireoidismo estimula a diferenciação das células da placa epifisária de ratas adultas, mas em crianças inicialmente acelera o crescimento ósseo e posteriormente inibe a proliferação dos condrócitos $(26,27)$ e fecha mais cedo as placas epifisárias $(1,27)$.

Sabe-se que os hormônios tireoidianos direta ou indiretamente aceleram o turnover ósseo, encurtando o ciclo de remodelação, mas por mecanismos ainda não elucidados (11). Enquanto T3 reduz a massa óssea, já foi demonstrado que o composto tireomimético TR beta-seletivo (GC-1) não causa osteopenia, o que sugere que essa isoforma de receptor não tem papel importante na gênese da osteopenia induzida pela tireotoxicose (28). Apesar da foliculogênese ter sido alterada no hipertireoidismo (dados já publicados) (29), o excesso dos hormônios tireoidianos não parece ter causado alteração óssea mediada por disfunção das gônadas, já que o hipertireoidismo não alterou significativamente os valores plasmáticos de estradiol e de progesterona (29).

A administração de tiroxina às ratas castradas conseguiu reverter a osteopenia somente aos 30 e 60 dias, tanto pela diminuição da reabsorção óssea como pelo aumento da aposição e retorno do crescimento longitudinal do osso. Já foi descrito que a resposta do osso de ratas castradas à tiroxina é dose dependente, de sorte que, em quantidades fisiológicas, a tiroxina repõe a massa óssea e, em doses maiores, a diminui (30). No presente trabalho, a prevenção ou a recomposição da perda óssea pareceu ser mais tempo-dependente, já que a dose utilizada, embora muito elevada, conseguiu prevenir ou reverter a osteopenia até os 60 dias, mostran- do efeito contrário somente aos 90 dias, por razões que não puderam ser elucidadas no presente estudo.

Vários são os relatos de que o hipertireoidismo associado à menopausa é de maior risco para o aparecimento da osteoporose, pois potencializa a osteopenia desencadeada pela deficiência dos esteróides sexuais $(11,12,31)$. A crença é que gônadas funcionais minimizam o efeito osteopênico do hipertireoidismo (32). Os resultados aqui obtidos mostram que, aos 90 dias, a intensidade da osteopenia foi semelhante nas ratas castradas independente de serem hipertireóideas ou não. Assim, os indícios são de que o hipertireoidismo não intensifica as alterações ósseas do hipogonadismo, mas causa osteopenia de maior extensão (atingindo maior número de unidades esqueléticas).

Há muita controvérsia no que concerne aos sítios preferenciais da osteopenia no hipogonadismo e no hipertireoidismo. Alguns autores relatam, na castração, perda óssea maior na tíbia do que nas vértebras lombares (33) e acometendo somente o tecido ósseo trabecular (34). Com relação ao hipertireoidismo, alguns apontam para a perda somente do osso cortical $(11,35)$, enquanto outros afirmam que a perda acomete tanto o osso trabecular quanto o cortical $(12,36)$. No presente trabalho, a osteopenia, independente da causa, acometeu primeiro os sítios de maior fluxo ósseo, ou seja, na seguinte ordem: osso alveolar, vértebras lombares, vértebras torácicas, ossos longos (tíbia proximal e fềmur distal e proximal) e vértebras cervicais. Além do mais, a osteopenia acometeu primeiro o tecido ósseo trabecular, sabidamente de maior turnover, estendendo-se posteriormente ao osso cortical, de turnover mais lento. É provável que no hipertireoidismo tenha ocorrido osteopenia somente do tecido ósseo trabecular em decorrência do tempo, talvez insuficiente para afetar o tecido ósseo cortical.

Conclui-se que o hipoprogesteronismo e o hiperestrogenismo alteram o metabolismo ósseo, e que a resposta do osso ao hipertireoidismo depende do perfil plasmático dos esteróides sexuais, do tempo de exposição e da configuração do tecido ósseo.

\section{AGRADECIMENTOS}

Este trabalho foi financiado pela Fundação de Amparo à Pesquisa de Minas Gerais (FAPEMIG CAG899/97). 


\section{REFERÊNCIAS}

1. Bland R. Steroid hormone receptor expression and action in bone. Clin Sci 2000;98:217-40.

2. Raisz LG. Physiology and pathophysiology of bone remodeling. Clin Chem 1999;45:1353-8.

3. Avioli VL, Krane SM. Metabolic bone disease. San Diego: Academic Press; 1998.

4. Bilezikian JP, Raisz LG, Rodan GA. Principles of bone biology. San Diego: Academic Press; 1996.

5. Meunier PJ, Bianchi GGS, Eduard CM, Bernard JC, Courpron P, Vignon GE. Bony manifestations of thyrotoxicosis. Orthop Clin N Am 1972;3:745-74.

6. Auwerx J, Bouillon R. Mineral and bone metabolism in thyroid disease: a review. Q J Med 1986;60:737-52.

7. Mosekilde L, Eriksen EF, Charles P. Effects of thyroid hormones on bone and mineral metabolism. Endocrinol Metab Clin N Am 1990;19:35-63.

8. Mundy GR, Shapiro JL, Bandelin JG, Canalis EM, Raisz LG. Direct stimulation of bone resorption by thyroid hormones. J Clin Invest 1976;58:529-34.

9. Allain TJ, Chambers TJ, Flanagan AM, McGregor AM. Triiodothyronine stimulates rat osteoclastic bone resorption by an indirect effect. J Endocrinol 1992;133:327-31.

10. Eriksen EF, Mosekilde L, Melsen F. Trabecular bone remodeling and bone balance in hyperthyroidism. Bone 1985;6:421-8.

11. Greenspan SL, Greenspan MD. The effect of thyroid hormone on skeletal integrity. Ann Intern Med 1999;130:750-8.

12. Campos-Pastor MM, Muñoz-Torres $M$, Escobar-Jiménez F, Almodóvar MR, Gimeno EJ. Bone mass in females with different thyroid disorders: influence of menopausal status. Bone Miner 1993;21:1-8.

13. Sampaio IBM. Estatística aplicada à experimentação animal. Belo Horizonte: FEP/MVZ, 1998.

14. Kalu DN, Hardin RR, Cockerham R. Evaluation of the pathogenesis of skeletal changes in ovariectomized rats. Endocrinology 1984;115:507-12.

15. Wronski TJ, Lowry PL, Walsh CC, Ignaszewski LA. Skeletal alterations in ovariectomized rats. Calcif Tissue Int 1985; 37:324-8.

16. Barengolts El, Gajardo HF, Rosol TJ, D'anza JJ, Pena M, Borsis J, et al. Effects of progesterone on postovariectomy bone loss in aged rats. J Bone Mineral Res 1990;11:1143-7.

17. Gallagher JC, Kable WT. Effect of progestin therapy on cortical and trabecular bone: comparison with estrogen. Am J Med 1991;90:171-8.

18. Rickard DJ, Waters KM, Ruesink TJ, et al. Estrogen receptor isoform-especifc induction of progesterone receptors in human osteoblasts. J Bone Miner Res 2002: 17:580-92.
19. Ishida Y, Tertinegg I, Heershe JNM. Progesterone and dexamethasone stimulate proliferation and differentiation of osteoprogenitors and progenitors for adipocytes and macrophages in cell populations derived from adult rat vertebrae. J Bone Miner Res 1996; 11:921-30.

20. Mac Namara $P$, Loughrey HC. Progesterone receptor $A$ and $B$ isoform expression in human osteoblasts. Calcif Tissue Int 1998;63:39-46.

21. Langdahl BL, Loft AG, Moller N, Weeke J, Eriksen EF, Mosekilde $L$, et al. Is skeletal responsiveness to thyroid hormone altered in primary osteoporosis or following estrogen replacement therapy? J Bone Miner Res 1997; 12:78-88.

22. Schoutens A, Laurent E, Markowicz E, Lisart J, Maertelaer VD. Serum triiodothyronine, bone turnover, and bone mass changes in euthyroid pre- and postmenopausal women. Calcif Tissue Int 1991;49:95-100.

23. Sontag W. Quantitative measurements of periosteal and cortical-endosteal bone formation and resorption in the midshaft of female rat femur. Bone 1986;7:55-62.

24. Dawson $A B$. The age order of epiphyseal union in the long bones of the albino rat. Anat Rec 1925;31:1-16.

25. Stark C, Kahrmann B, Walzel E. Epi- and metaphyseal morphology in the long bones of BDIX/Han rats. Lab Anim 1996;30:35-41.

26. Ishikawa Y, Genge BR, Wuthier RE, Wu LNY. Thyroid hormone inhibits growth and stimulates Terminal differentiation of epiphyseal growth plate chondrocytes. J Bone Miner Res 1998;13:1398-411.

27. Williams GR, Robson H, Shalet SM. Thyroid hormone actions on cartilage and bone: interactions with other hormones at the epiphyseal plate and effects on linear grwth. J Endocrinol 1998;157:391-403.

28. Freitas FRS, Moriscot AS, Jorgetti V, Soares AG, Passarelli M, Scanlan TS, et al. Spared bone mass in rats treated with thyroid hormone receptor TR beta-selective compound GC-1. Am J Physiol Endocrinol Metab 2003;285:E1 135-41.

29. Serakides R, Nunes VA, Nascimento EF, Ribeiro AFC, Silva CM. Foliculogênese e esteroidogênese ovarianas em ratas adultas hipertireóideas. Arq Bras Endocrinol Metab 2001;45:258-64.

30. Gouveia CHA, Jorgetti V, Bianco AC. Effects of thyroid hormone administration and estrogen deficiency on bone mass of female rats. J Bone Miner Res 1997; 12:2098-107.

31. Giannini S, Nobile M, Sartori L, Binotto P, Ciufreda M, Gemo $G$, et al. Bone density and mineral metabolism in thyroidectomized patients treated with long-term Lthyroxine. Clin Sci 1994;87:593-7.

32. Faber J, Galloe AM. Changes in bone mass during prolonged subclinical hyperthyroidism due to L-thyroxine treatment: a meta-analysis. Eur J Endocrinol 1994; 130:350-6.

33. Wronski TJ, Walsh CC, Ignaszewski LA. Histologic evidence for osteopenia and increased bone turnover in ovariectomized. Bone 1986;7:1 19-23. 
34. Kimmel DB, Wronski TJ. Nondestructive measurement of bone mineral in femurus from ovariectomized rats. Calcif Tissue Int 1990;46:101-10.

35. Suwanwalaikorn S, Ongphipha-Dhanakul B, Braverman LE, Baran DT. Differential responses of femoral and vertebral bones to long-term excessive L-thyroxine administration in adult rats. Eur J Endocrinol 1996; 134:655-9.

36. Yamamoto $M$, Markatos A, Seedor JG, Masarachia $P$, Gentile M, Rodan GA, et al. The effects of the aminobisphosphonate alendronate on thyroid hormone-induced osteopenia in rats. Calcif Tissue Int 1993;53:278-82.

\section{Endereço para correspondência}

Rogéria Serakides

Setor de Patologia

Departamento de Clínica e

Cirurgia Veterinárias da UFMG

Av. Pres. Antônio Carlos 6627

Caixa Postal 567

31270-901 Belo Horizonte, MG

Fax: (31) 3499-2230

E-mail: serakide@dedalus.lcc.ufmg.br 